\title{
Community-level facilitation by macroalgal foundation species peaks at an intermediate level of environmental stress
}

\author{
Ricardo A. Scrosati \\ St. Francis Xavier University, Department of Biology, 2320 Notre Dame Avenue, Antigonish, Nova Scotia B2G 2 W5, Canada
}

In rocky intertidal habitats, abiotic stress due to desiccation and thermal extremes increases with elevation because of tides. A study in Atlantic Canada showed that, at low elevations where conditions are benign due to the brief low tides, fucoid algal canopies (Ascophyllum nodosum and Fucus spp.) do not affect the structure of benthic communities. However, at middle and high elevations, where low tides last longer, fucoid canopies limit abiotic extremes and increase the richness (number of invertebrate and algal species, except fucoids) of benthic communities. Using the data from that study, this paper compares the intensity of facilitation and its importance (relative to all other sources of variation in richness) between middle and high elevations, which represent intermediate and high stress, respectively. Facilitation intensity was calculated as the percent increase in benthic richness between quadrats with low and high canopy cover, while the importance of facilitation was calculated as the percentage of variation in richness explained by canopy cover. Data for 689 quadrats spanning $350 \mathrm{~km}$ of coastline were used. Both the intensity and importance of facilitation were greater at middle elevations than at high elevations. As canopies do not affect benthic communities at low elevations, this study suggests that the facilitation-stress relationship at the community level is unimodal for this marine system. Such a pattern was found for some terrestrial systems dominated by canopy-forming plants. Thus, it might be ubiquitous in nature and, as further studies refine it, it might help to predict community-level facilitation depending on environmental stress.

Key Words: Ascophyllum; canopy; facilitation; Fucus; intertidal; species richness; understory

\section{INTRODUCTION}

In ecology, facilitation refers to the improvement of species performance caused directly or indirectly by another species (Bruno et al. 2003, Bulleri et al. 2016, Michalet and Pugnaire 2016). Common facilitators are organisms that ameliorate abiotic conditions in environmentally stressful habitats. Examples are alpine cushion plants, which protect smaller plants from cold and wind (Ballantyne and Pickering 2015), desert shrubs, which locally decrease heat and water loss (Pugnaire et al. 2011, Ruttan et al. 2016), and intertidal macroalgae, which limit benthic thermal stress and desiccation at low tide (Bertness et al. 1999, Beermann et al. 2013). The possession of extensive canopies is central to the ability of such species to positively affect others. Because of their influence on entire communities through those mechanisms, those organisms are often referred to as foundation species (Altieri and van de Koppel 2014).

The intensity of facilitation by canopy-forming species depends on the degree of environmental stress. Studies in aquatic and terrestrial communities have consistently
(P) $\$$ This is an Open Access article distributed under the terms of the Creative Commons Attribution Non-Commercial License (http://creativecommons.org/licenses/by-nc/3.0/) which permits unrestricted non-commercial use, distribution, and reproduction in any medium, provided the original work is properly cited.
Received January 8, 2017, Accepted February 20, 2017

* Corresponding Author

E-mail: rscrosat@stfx.ca

Tel: +1-902-867-5289, Fax: +1-902-867-2389 


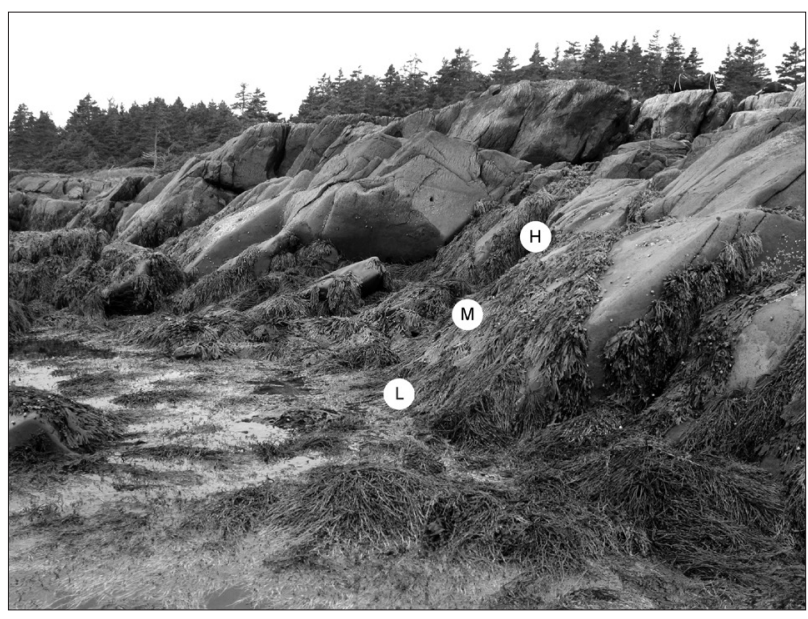

Fig. 1. Wave-sheltered rocky intertidal habitat from the Atlantic coast of Nova Scotia viewed at low tide, showing the extensive cover of fucoid algal canopies at high $(\mathrm{H})$, middle $(\mathrm{M})$, and low (L) elevations. Picture taken by the author.

found that positive effects are common under abiotically stressful conditions but weak or absent under benign conditions (He et al. 2013). That is a central component of the stress gradient hypothesis (Bertness and Callaway 1994), which has frequently been used to assume a continuous increase in facilitation intensity with abiotic stress (Maestre et al. 2009). More recent studies have began to evaluate if the intensity of facilitation may actually often have a unimodal relationship with stress, especially when facilitation is evaluated at the community level (Michalet et al. 2006, Brooker et al. 2008, Holmgren and Scheffer 2010). An important reason for such a pattern could be that, under extreme stress, facilitators may be unable to ameliorate conditions strongly enough for many species (Holmgren and Scheffer 2010, He and Bertness 2014, Michalet et al. 2014). This paper investigates the facilitation-stress relationship at the community level using data from rocky intertidal systems.

The intertidal zone is the area of a marine coast between the highest and lowest tidal levels. As low tides become longer with intertidal elevation, biological desiccation and thermal extremes increase with elevation because of the longer exposure to the air (Raffaelli and Hawkins 1999, Menge and Branch 2001). For example, in the summer on cold-temperate shores, daily maximum temperature can be $10^{\circ} \mathrm{C}$ higher and algal desiccation during low tides four times higher at high elevations than at low elevations (Eckersley and Scrosati 2012). On NW Atlantic rocky shores, fucoid seaweed canopies (Ascophyllum nodosum (Linnaeus) Le Jolis and Fucus spp.) often cover the substrate extensively from low to high elevations in wavesheltered habitats (Adey and Hayek 2005, Longtin et al. 2009) (Fig. 1). Due to the limited aerial exposure at low elevations, fucoid canopies in such places have almost no influence on benthic temperature and do not affect the structure of benthic communities. However, with the longer aerial exposure at high and middle elevations, fucoid canopies limit the otherwise high thermal extremes and, in that way, increase the richness (number of species) of benthic communities (Watt and Scrosati 2013a, 2013b). As fucoid canopies do not affect benthic richness at low elevations, this paper evaluates the occurrence of a unimodal facilitation-stress relationship by testing the hypothesis that the positive effect that canopies have on benthic richness at middle and high elevations is greatest at middle elevations.

\section{MATERIALS AND METHODS}

The occurrence of facilitation by fucoid canopies at high and middle elevations and its absence at low elevations were shown by a regional-scale mensurative study (Watt and Scrosati 2013b) and a local-scale manipulative experiment (Watt and Scrosati 2013a). As both approaches led to the same such conclusion, the hypothesis of the present study is hereby tested using the mensurative dataset because of its larger size $(760 \%$ more replicates), which was expected to aid the statistical detection of differences in facilitation intensity betwen middle and high elevations. In addition, the mensurative dataset summarizes years of canopy influences on bentic communities under natural conditions, while the manipulative dataset describes only one year of canopy influences while benthic communities recovered after substrate clearings. Although the ongoing recovery was enough to show facilitation at high and middle elevations (Watt and Scrosati 2013a), species richness was still limited compared with pristine communities (Watt and Scrosati 2013b), rendering the manipulative dataset less adequate to test differences in facilitation intensity between high and middle elevations. The mensurative approach has been widely used in facilitation research involving terrestrial systems, which largely constitutes the basis for current facilitation theory (Soliveres et al. 2015, Michalet and Pugnaire 2016).

The full dataset used for the present study has been published in a separate data paper (Watt and Scrosati 2014). The methodology of the study for which those data were gathered is described in the corresponding paper (Watt and Scrosati 2013b), but it is summarized here to 

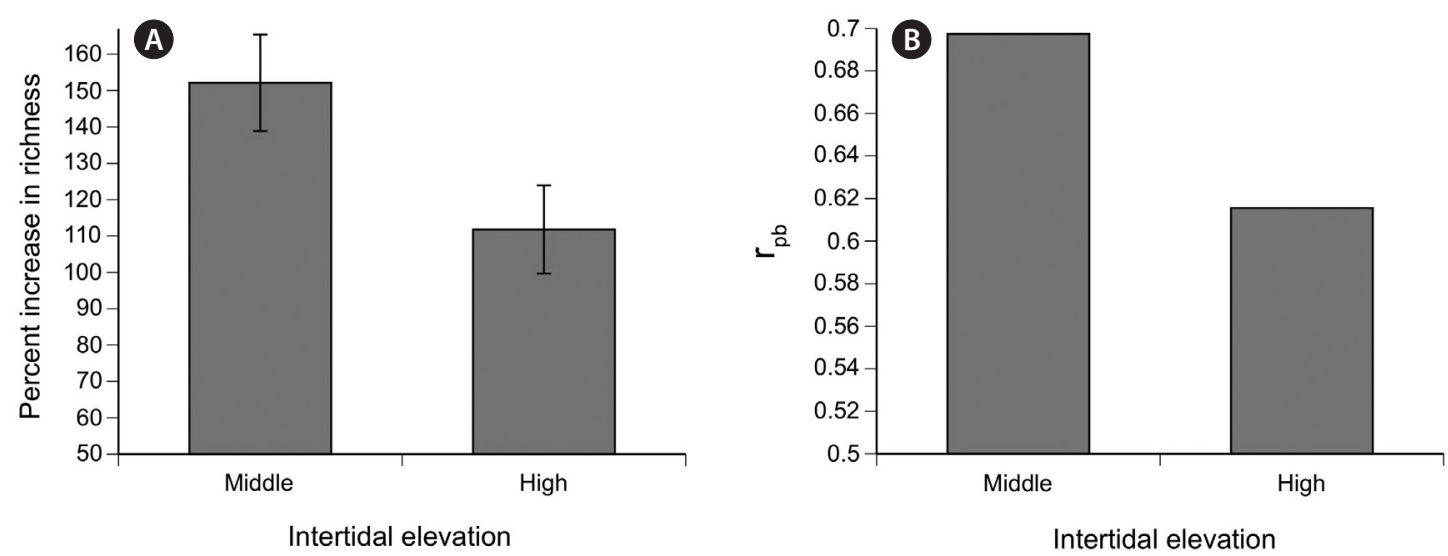

Fig. 2. (A) Percent increase in benthic species richness between quadrats with low and high canopy cover (facilitation intensity; mean $\pm \mathrm{SE}$ ) at middle and high intertidal elevations. (B) Point-biserial correlation coefficients $\left(r_{p b}\right)(p<0.001$ in both cases) used to calculate the importance of facilitation at middle and high elevations. Both descriptors of facilitation differed significantly between middle and high elevations (see Results for details).

highlight the main aspects. The data were measured in wave-sheltered rocky intertidal habitats spanning $350 \mathrm{~km}$ of the Atlantic coast of Nova Scotia, Canada. The studied canopies have a similar composition of fucoid algae (Fucaceae) at low (0-0.5 $\mathrm{m}$ above chart datum), middle (0.5-1 $\mathrm{m})$, and high (1-1.5 m) elevations, with a predominance of Ascophyllum nodosum (59-72\%) followed by Fucus vesiculosus Linnaeus (26-34\%) and three other species of Fucus $(<1-7 \%)$. To assess whether canopy effects on benthic richness existed at each elevation zone, all algae and invertebrates found in replicate quadrats $(20 \mathrm{~cm} \times 20 \mathrm{~cm})$ randomly placed at each zone were identified. For consistency, quadrats were not placed on crevices. For each elevation zone, canopy effects were looked for by comparing richness between two canopy cover treatments: low $(0-40 \%)$ and high $(60-100 \%)$ cover. Since fucoid canopies only influenced richness at high and middle elevations (Watt and Scrosati 2013b), only data for such elevations were necessary to test the hypothesis of this study. The number of surveyed quadrats was 234 (low canopy cover) and 110 (high canopy cover) at high elevations and 111 (low canopy cover) and 234 (high canopy cover) at middle elevations. For these two elevation zones, a total of 16 seaweeds (excluding the fucoid species) and 41 invertebrates were identified (see the species list in Watt and Scrosati 2013b).

For this study, both the intensity and importance (Brooker et al. 2008) of whole-community facilitation by fucoid canopies were compared between high and middle elevations. Facilitation intensity was calculated for each elevation zone as the percent increase in richness between the low-cover and high-cover treatments. For high elevations, the 110 high-cover quadrats were randomly paired with 110 low-cover quadrats selected at random while, for middle elevations, the 111 low-cover quadrats were randomly paired with 111 high-cover quadrats also selected at random. For each resulting pair of quadrats, the percent change in richness was calculated as $\left\{\left[\left(S_{H}\right.\right.\right.$ $\left.\left.\left.S_{L}\right) / S_{L}\right] \times 100\right\}$, where $S_{H}$ was species richness in the highcover quadrat and $S_{L}$ was richness in the low-cover quadrat. Thus calculated, facilitation intensity was statistically compared between high and middle elevations through a two-sample t-test (Howell 2002).

The importance of facilitation was calculated for each elevation zone using the point-biserial correlation coefficient $\left(\mathrm{r}_{\mathrm{pb}}\right)$. To calculate $\mathrm{r}_{\mathrm{pb}}$ for each zone, richness was considered as the dependent variable and the two canopy cover treatments were considered as the independent variable, coding low cover as "1" and high cover as " 2 " (Fritz et al. 2012). The percent $\mathrm{r}_{\mathrm{pb}}{ }^{2}$ was calculated to indicate the percentage of variation in richness that could be explained by canopy cover, which was considered as the importance of whole-community facilitation $\left(r_{\mathrm{pb}}\right.$ being positive) relative to all other sources of variation in richness. The point-biserial correlation coefficient was statistically compared between high and middle elevations using the one-tailed $\mathrm{Z}$ test designed to compare two independent $r$ values under a directional alternative hypothesis (Howell 2002).

The analyses described above tested the hypothesis of this study at the patch (quadrat) scale. The difference in facilitation intensity between middle and high elevations was also evaluated at the whole-habitat scale (Cavieres et al. 2016). For this purpose, the total number of species 
found only under high canopy cover, only under low cover, and in both cover treatments (Armas et al. 2011) was calculated for middle and high elevations using the information provided in Table 2 in Watt and Scrosati (2013b).

\section{RESULTS}

At the patch scale, the intensity of community-level facilitation by fucoid canopies was, on average, $36 \%$ higher at middle elevations than at high elevations, which was a significant difference $\left(t_{219}=2.25, p=0.026\right)$ (Fig. 2A). The importance of community-level facilitation was also higher at middle elevations, as fucoid canopy cover explained $49 \%$ (percent $\mathrm{r}_{\mathrm{pb}}{ }^{2}$ ) of the observed variation in benthic richness at middle elevations and 38\% at high elevations. The point-biserial correlation coefficient $\left(\mathrm{r}_{\mathrm{pb}}\right)$ was significantly higher at middle elevations than at high elevations ( $\mathrm{Z}=1.88, \mathrm{p}=0.030$ ) (Fig. $2 \mathrm{~B}$ ).

At the whole-habitat scale, 26 of the 57 species $(46 \%)$ identified at middle elevations were only present under high canopy cover, while no species $(0 \%)$ were only present under low cover. At high elevations, however, just 11 of the identified 30 species (37\%) were only present under high canopy cover, while 3 of those 30 species $(10 \%)$ were only present under low cover.

\section{DISCUSSION}

Intertidal fucoid canopies were recently found to increase benthic species richness at middle and high elevations (Watt and Scrosati 2013a, 2013b). The present study has revealed that such effects are greater at middle elevations in terms of both intensity and importance of facilitation. As fucoid canopies have no effects on benthic communities at low elevations (Watt and Scrosati 2013a, 2013b), these overall findings support the unimodal facilitation-stress hypothesis (Michalet et al. 2006, Holmgren and Scheffer 2010). In other words, community-level facilitation by intertidal fucoid canopies peaks at an intermediate level of environmental stress represented by middle elevations.

A variety of mechanisms have been proposed to explain the drop in facilitation intensity from intermediate to high stress levels (Michalet and Pugnaire 2016). When effects are analyzed at the community level (as in this study), a commonly proposed mechanism is the decreasing ability of facilitators to improve conditions strongly enough for some species towards the highest stress levels where the facilitators occur (Holmgren and Scheffer 2010, He and Bertness 2014, Michalet et al. 2014). For intertidal communities as a whole, physiological stress (mainly due to high temperature and desiccation during low tides) peaks at high elevations (Raffaelli and Hawkins 1999, Menge and Branch 2001). However, at high elevations, fucoid canopies were found to be unable to limit mean temperature as strongly as at middle elevations (Watt and Scrosati 2013a). Thus, these observations lend support to the above explanation. Studies on the physiological influence of fucoid canopies on the benthic species found at high and middle elevations (currently lacking) could contribute to strengthen this view.

Another explanation for facilitation decreasing at high stress relates to structural changes in the facilitators. For example, Bonanomi et al. (2016) found a hump-shaped relationship between altitude on mountain sides (proxy for cold and wind stress) and the intensity of facilitation by cushion plants on associated plant richness. The decreasing facilitation at high altitudes seemed to result mainly from an increase in cushion compactness, which may have limited the ability of cushions to trap seeds of other plants and / or enable their root development (Bonanomi et al. 2016). This was not the case for intertidal fucoid canopies, however. These canopies are extensive but do not increase in compactness towards high elevations. Moreover, the canopies arise from relatively small holdfasts (the structures that keep algae attached to the substrate), leaving ample substrate for other benthic species to occur. Another suggested explanation for the decrease in facilitation at high stress involves increasing competition. For example, when stress peaks due to intense water loss in the soil, canopy-forming plants may actually compete for water with the associated plants, which can limit or even eliminate facilitation (Holmgren et al. 2012, Michalet et al. 2014, Butterfield et al. 2016). However, this explanation is not applicable to the studied intertidal habitats either, because benthic algae and sessile invertebrates are attached to solid bedrock in these places.

Regardless of the underlying mechanism, decreases in facilitation intensity from intermediate to high stress levels have been found for additional systems recently (de Bello et al. 2011, Koyama and Tsuyuzaki 2013, Castanho et al. 2015). Overall, these findings point to the more complex nature of the facilitation-stress relationship than originally envisioned. In this sense, the contribution of the present study is important because it is based on data for the entire community, including primary producers as well as consumers. This is relevant because most facilita- 
tion studies have investigated effects on a few associated species or, when looking at the multispecies level, often only on the assemblage of associated plants (Soliveres et al. 2015, Bonanomi et al. 2016, Cavieres et al. 2016, López et al. 2016). Recent studies are recognizing the need to evaluate facilitation effects at the whole-community level, including plants and animals, to develop a broader conceptual understanding of the facilitation-stress relationship (Lortie et al. 2016, Ruttan et al. 2016).

\section{ACKNOWLEDGEMENTS}

The author appreciates funding through a Discovery Grant from the Natural Sciences and Engineering Research Council (NSERC) and through a Leaders Opportunity Grant from the Canada Foundation for Innovation (CFI).

\section{REFERENCES}

Adey, W. H. \& Hayek, L.-A. C. 2005. The biogeographic structure of the western North Atlantic rocky intertidal. Cryptogam. Algol. 26:35-66.

Altieri, A. H. \& van de Koppel, J. 2014. Foundation species in marine ecosystems. In Bertness, M. D., Bruno, J. F., Silliman, B. R. \& Stachowicz, J. J. (Eds.) Marine Community Ecology and Conservation. Sinauer Associates, Sunderland, MA, pp. 37-56.

Armas, C., Rodríguez-Echeverría, S. \& Pugnaire, F. I. 2011. A field test of the stress-gradient hypothesis along an aridity gradient. J. Veg. Sci. 22:818-827.

Ballantyne, M. \& Pickering, C. M. 2015. Shrub facilitation is an important driver of alpine plant community diversity and functional composition. Biodivers. Conserv. 24:1859-1875.

Beermann, A. J., Ellrich, J. A., Molis, M. \& Scrosati, R. A. 2013. Effects of seaweed canopies and adult barnacles on barnacle recruitment: the interplay of positive and negative influences. J. Exp. Mar. Biol. Ecol. 448:162-170.

Bertness, M. D. \& Callaway, R. 1994. Positive interactions in communities. Trends Ecol. Evol. 9:191-193.

Bertness, M. D., Leonard, G. H., Levine, J. M., Schmidt, P. R. \& Ingraham, A. O. 1999. Testing the relative contribution of positive and negative interactions in rocky intertidal communities. Ecology 80:2711-2726.

Bonanomi, G., Stinca, A., Battista Chirico, G., Ciaschetti, G., Saracino, A. \& Incerti, G. 2016. Cushion plant morphology controls biogenic capability and facilitation effects of
Silene acaulis along an elevation gradient. Funct. Ecol. 30:1216-1226.

Brooker, R. W., Maestre, F. T., Callaway, R. M., Lortie, C. L., Cavieres, L. A., Kunstler, G., Liancourt, P., Tielbörger, K., Travis, J. M. J., Anthelme, F., Armas, C., Coll, L., Corcket, E., Delzon, S., Forey, E., Kikvidze, Z., Olofsson, J., Pugnaire, F., Quiroz, C. L., Saccone, P., Schiffers, K., Seifan, M., Touzard, B. \& Michalet, R. 2008. Facilitation in plant communities: the past, the present, and the future. J. Ecol. 96:18-34.

Bruno, J. F., Stachowicz, J. J. \& Bertness, M. D. 2003. Inclusion of facilitation into ecological theory. Trends Ecol. Evol. 18:119-125.

Bulleri, F., Bruno, J., Silliman, B. R. \& Stachowicz, J. J. 2016. Facilitation and the niche: implications for coexistence, range shifts, and ecosystem functioning. Funct. Ecol. 30:70-78.

Butterfield, B. J., Bradford, J. B., Armas, C., Prieto, I. \& Pugnaire, F. I. 2016. Does the stress-gradient hypothesis hold water? Disentangling spatial and temporal variation in plant effects on soil moisture in dryland systems. Funct. Ecol. 30:10-19.

Castanho, C. T., Oliveira, A. A. \& Prado, P. I. K. L. 2015. Does extreme environmental severity promote plant facilitation? An experimental field test in a subtropical coastal dune. Oecologia 178:855-866.

Cavieres, L. A., Hernández-Fuentes, C., Sierra-Almeida, A. \& Kikvidze, Z. 2016. Facilitation among plants as an insurance policy for diversity in Alpine communities. Funct. Ecol. 30:52-59.

de Bello, F, Doležal, J., Dvorský, M., Chlumská, Z., Řeháková, K., Klimešová, J. \& Klimeš, L. 2011. Cushions of Thylacospermum caespitosum (Caryophyllaceae) do not facilitate other plants under extreme altitude and dry conditions in the north-west Himalayas. Ann. Bot. 108:567-573

Eckersley, L. K. \& Scrosati, R. A. 2012. Temperature, desiccation, and species performance trends along an intertidal elevation gradient. Curr. Dev. Oceanogr. 5:59-73.

Fritz, C. O., Morris, P. E. \& Richler, J. J. 2012. Effect size estimates: current use, calculations, and interpretation. J. Exp. Psychol. Gen. 141:2-18.

He, Q. \& Bertness, M. D. 2014. Extreme stresses, niches, and positive species interactions along stress gradients. Ecology 95:1437-1443.

He, Q., Bertness, M. D. \& Altieri, A. H. 2013. Global shifts towards positive species interactions with increasing environmental stress. Ecol. Lett. 16:695-706.

Holmgren, M., Gómez-Aparicio, L., Quero, J. L. \& Valladares, F. 2012. Non-linear effects of drought under shade: rec- 
onciling physiological and ecological models in plant communities. Oecologia 169:293-305.

Holmgren, M. \& Scheffer, M. 2010. Strong facilitation in mild environments: the stress gradient hypothesis revisited. J. Ecol. 98:1269-1275.

Howell, D. C. 2002. Statistical methods for psychology. Duxbury, Pacific Grove, CA, 802 pp.

Koyama, A. \& Tsuyuzaki, S. 2013. Facilitation by tussockforming species on seedling establishment collapses in an extreme drought year in a post-mined Sphagnum peatland. J. Veg. Sci. 24:473-483.

Longtin, C. M., Scrosati, R. A., Whalen, G. B. \& Garbary, D. J. 2009. Distribution of algal epiphytes across environmental gradients at different scales: intertidal elevation, host canopies, and host fronds. J. Phycol. 45:820-827.

López, R. P., Squeo, F. A., Armas, C., Kelt, D. A. \& Gutiérrez, J. R. 2016. Enhanced facilitation at the extreme end of the aridity gradient in the Atacama Desert: a communitylevel approach. Ecology 97:1593-1604.

Lortie, C. J., Filazzola, A. \& Sotomayor, D. A. 2016. Functional assessment of animal interactions with shrub-facilitation complexes: a formal synthesis and conceptual framework. Funct. Ecol. 30:41-51.

Maestre, F. T., Callaway, R. M., Valladares, F. \& Lortie, C. J. 2009. Refining the stress-gradient hypothesis for competition and facilitation in plant communities. J. Ecol. 97:199-205.

Menge, B. A. \& Branch, G. M. 2001. Rocky intertidal communities. In Bertness, M. D., Gaines, S. D. \& Hay, M. E. (Eds.) Marine Community Ecology. Sinauer Associates, Sunderland, MA, pp. 221-251.

Michalet, R., Brooker, R. W., Cavieres, L. A., Kikvidze, Z., Lortie, C. J., Pugnaire, F. I., Valiente-Banuet, A. \& Callaway, R. M. 2006. Do biotic interactions shape both sides of the humped-back model of species richness in plant communities? Ecol. Lett. 9:767-773.
Michalet, R., Le Bagousse-Pinguet, Y., Maalouf, J. -P. \& Lortie, C. J. 2014. Two alternatives to the stress-gradient hypothesis at the edge of life: the collapse of facilitation and the switch from facilitation to competition. J. Veg. Sci. 25:609-613.

Michalet, R. \& Pugnaire, F. I. 2016. Facilitation in communities: underlying mechanisms, community and ecosystem implications. Funct. Ecol. 30:3-9.

Pugnaire, F. I., Armas, C. \& Maestre, F. T. 2011. Positive plant interactions in the Iberian Southeast: mechanisms, environmental gradients, and ecosystem function. J. Arid Environ. 75:1310-1320.

Raffaelli, D. \& Hawkins, S. J. 1999. Intertidal ecology. Chapman \& Hall, London, 356 pp.

Ruttan, A., Filazzola, A. \& Lortie, C. J. 2016. Shrub-annual facilitation complexes mediate insect community structure in arid environments. J. Arid Environ. 134:1-9.

Soliveres, S., Smit, C. \& Maestre, F. T. 2015. Moving forward on facilitation research: response to changing environments and effects on the diversity, functioning, and evolution of plant communities. Biol. Rev. Camb. Philos. Soc. 90:297-313.

Watt, C. A. \& Scrosati, R. A. 2013a. Bioengineer effects on understory species richness, diversity, and composition change along an environmental stress gradient: experimental and mensurative evidence. Estuar. Coast. Shelf Sci. 123:10-18.

Watt, C. A. \& Scrosati, R. A. 2013b. Regional consistency of intertidal elevation as a mediator of seaweed canopy effects on benthic species richness, diversity, and composition. Mar. Ecol. Prog. Ser. 491:91-99.

Watt, C. A. \& Scrosati, R. A. 2014. Experimental and mensurative data on the abundance of primary producers and consumers from intertidal habitats in Canada. Ecology 95:1429. 